\title{
O Currículo Paralelo dos Estudantes da Terceira Série do Curso Médico da Universidade Federal de Alagoas"
}

\author{
The "Parallel Curriculum" of Third-year \\ Medical Students of the Federal \\ University of Alagoas
}

PALAVRAS-CHAVE:

- Currículo;

- Educação de Graduação em Medicina; - Estudantes de Medicina.

KEY-WORDS:

- Curriculum;

- Education, Medical, Undergraduate:

- Students, Medical.

Recebido em: 31/08/2006

Reencaminhado em: 22/05/2007

Aprovado em: 23/05/2007
Carlos Henrique Falcão Tavares ${ }^{1}$ José Antonio Maia ${ }^{2}$ Marcella Cristina Halliday Muniz ${ }^{1}$ Moana Vergetti Malta ${ }^{1}$ Belmira Rita da Costa Magalhães ${ }^{1}$ Ana Claire Pimenteira Thomaz ${ }^{1}$

\section{R E S U M O}

O trabalho teve por objetivo caracterizar o currículo paralelo dos alunos da terceira série do curso médico da Universidade Federal de Alagoas, por meio de um questionário auto-aplicado a uma amostra de 63 alunos. Com base na análise dos dados, constatou-se que a maioria dos alunos (98,41\%) buscou algum tipo de atividade extracurricular, sendo que 45,59\% delas foram realizadas no período de seis meses, consumindo mais de seis horas semanais. As principais motivações citadas foram a "busca da prática" na atividade médica (36,27\%) e a "aquisição de novos conhecimentos" (30,39\%). Nota-se que 98,39\% dos alunos optaram principalmente por estágios, sendo as principais formas de ingresso os concursos (52\%) e a seleção (36\%). Concluise que, durante a terceira série do curso médico, os alunos ainda não estão capacitados para atuar nos diversos serviços e, por vezes, prejudicam suas atividades acadêmicas para realizar os estágios. Cabe à Universidade orientar seus alunos quanto ao momento mais adequado para o início dessas atividades, além de oferecer suporte quando da realização das mesmas.

\section{A B S T R A C T}

The aim of this investigation was to characterize the parallel curriculum of third-year medical students of the Federal University of Alagoas by using a self-applied questionnaire, which was answered by 63 students. The data obtained showed that the greater part of students (98.41\%) had developed some kind of extra-curricular activity. $45.59 \%$ of these activities had been carried out during a six month's period and occupied more than six hours a week. The reasons that most frequently motivated these activities were getting practice at medical activities (36.27\%) and acquiring new knowledge (30,39\%). 98.39\% of the students had opted for training periods to which they were admitted by public competition (52\%) or admission tests (36\%). It is concluded that in the third year of the Medical course students are still not qualified for the different services and the extra-curricular training periods many times hamper their academic performance. It is thus responsibility of the University to guide the students, show them the right moment to start such activities and to offer support to these initiatives 


\section{INTRODUÇÃO}

Observando-se os diversos serviços de saúde da cidade de Maceió, pode-se identificar uma realidade que tem uma importância potencialmente significativa no contexto da formação médica na Universidade Federal de Alagoas: os estudantes estão realizando estágios nos primeiros anos do curso, sem ao menos terem concluído a disciplina de Semiologia Médica, inclusive faltando a atividades acadêmicas para comparecer a esses plantões. Os alunos chegam a pagar por "cursinhos" para concorrer a vagas em diversos estágios.

Como a nova proposta do Curso Médico da Ufal ${ }^{1}$ inclui um planejamento de inserção dos alunos na prática profissional de forma crescente em complexidade e sob supervisão docente, essa constatação despertou o interesse em estudar mais profundamente tal realidade, no contexto da formação e do aperfeiçoamento do currículo.

A palavra curriculum parece ter sido usada pela primeira vez no início do século 16, na Universidade de Glasgow, com o sentido de curso de estudos ${ }^{2}$. Muito tempo depois, Goodson ${ }^{3}$ apresenta uma visão do currículo como uma resultante de um processo social, em constante tensão e transformação, sendo inclusive campo de conflitos de diferentes visões e concepções sociais. Assim, a inclusão ou exclusão de uma disciplina ou de uma atividade acadêmica no currículo reflete processos semelhantes aos que ocorrem no contexto social, legitimados em determinado tempo histórico num documento sujeito a novas e constantes mudanças.
Todavia, um conceito ainda mais amplo de currículo o apresenta como4:

(...) uma construção social da escola, um instrumento pelo qual ela delimita um espaço onde vão ocorrer as experiências de ensino e aprendizagem, com vistas a um processo de formação, em um determinado nível de educação escolar, durante um certo período de tempo. Este espaço é configurado e constantemente reconfigurado, considerando-seo caráter dinâmico do conhecimento e da cultura que devem ser escolarizados, ante a formação do aluno para um conjunto de necessidades sociais. (p. 104)

Desta forma, é por intermédio do planejamento curricular que são "escolarizadas" experiências de ensino-aprendizagem consideradas relevantes para o desenvolvimento do estudante, de acordo com o perfil profissional de egresso que se deseja formar.

Observa-se, entretanto, que nem todas as experiências de formação que integram o currículo (na visão mais ampla apresentada) são planejadas, ou sequer conhecidas. Na verdade, a elaboração curricular geralmente resulta na geração de documentos oficiais que apresentam o currículo formal, estabelecendo a organização e a distribuição das disciplinas, com seus objetivos, conteúdos programáticos, estratégias didáticas e procedimentos de avaliação ${ }^{5}$. Para além desta formalidade situamse diversas atividades e influências ambientais difíceis de serem conhecidas e transformadas. A Figura 1 apresenta, de forma esquemática, os diversos "currículos" que integram a formação do estudante.

Figura 1.

Currículo Formal, Informal, Escolar, Paralelo e Oculto. Movimentos do planejamento curricular (reproduzido de Maia, 2005 ${ }^{6}$ ).

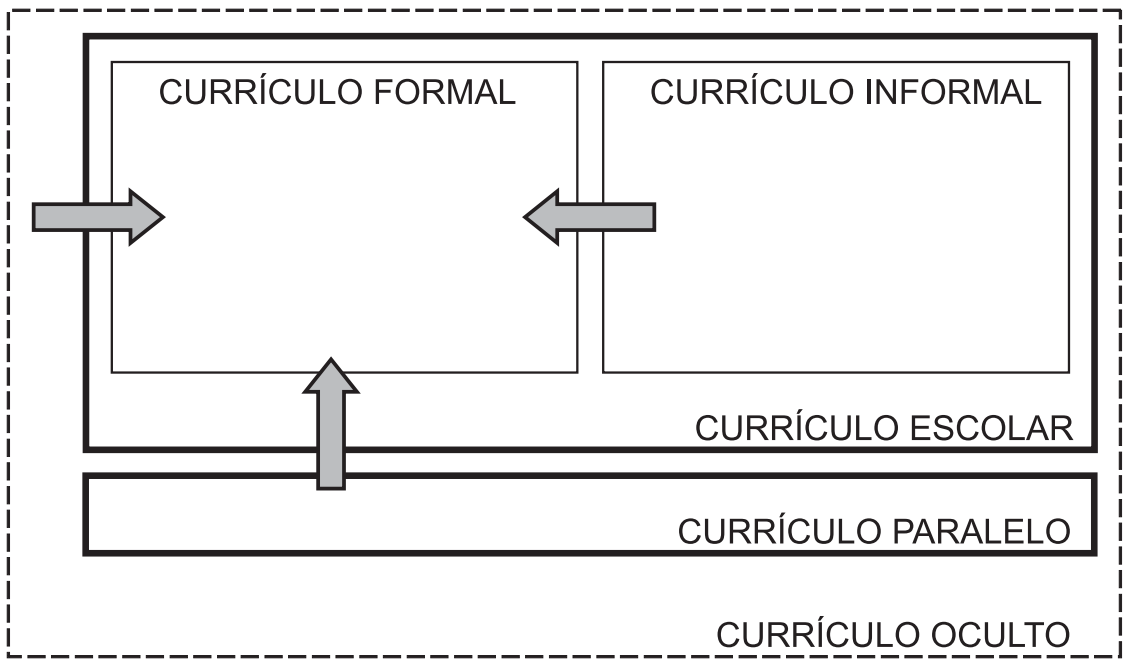


Embora haja algum grau de divergência conceitual entre diferentes autores, podemos considerar que o currículo informal é composto pelo conjunto de experiências de formação buscadas pelos estudantes no interior da própria instituição, ao passo que no currículo paralelo se situam as atividades que estes realizam fora do ambiente da academia ${ }^{6}$. Integram este segundo contexto estágios, plantões e outras modalidades de busca de aprendizagem, geralmente ligadas à prática. Por sua vez, o currículo oculto perpassa todos os demais "currículos", estabelecendo-se como um "pano de fundo" em todo o processo de formação. É nele que se situa o vasto conjunto de experiências de formação que ocorrem de forma não intencional, ligadas, principalmente, ao desenvolvimento de valores e atitudes ${ }^{7}$.

Assim, se considerarmos o currículo escolar como o conjunto das atividades formais e informais, podemos afirmar que o currículo paralelo se situa no espaço "extramuros", sendo "o conjunto de atividades extracurriculares que os alunos desenvolvem, subvertendo, na maioria das vezes, a estrutura curricular formal estabelecida pela faculdade" ${ }^{\prime 5}$.

Para a análise dos dados do presente trabalho, a expressão "extracurricular" refere-se ao conjunto de atividades realizadas pelos estudantes fora do ambiente acadêmico, correspondendo, portanto, principalmente ao currículo paralelo, de acordo com os conceitos acima. Entretanto, deve ser mais uma vez ressaltada a influência do currículo oculto também nesses ambientes de estágio e aprendizagem.

Este conceito permite uma visão mais ampliada do que realmente ocorre no processo de formação de nossos estudantes, podendo fornecer dados que logrem aprimorar o currículo formal. Neste sentido, a Figura 1 apresenta alguns movimentos de planejamento educacional, trazendo para o currículo formal as experiências positivas situadas nos demais "currículos". Especificamente no que se refere ao currículo paralelo, há um potencial muito grande para serem realizadas parcerias da academia com os serviços, uma vez que estes são geralmente os espaços da prática profissional buscados pelos estudantes ${ }^{8}$.

O presente trabalho situa-se num momento de mudança curricular na Universidade Federal de Alagoas (Ufal), que ocorre no contexto do Promed, de modo a contribuir com outras pesquisas que vêm demonstrando uma grande freqüência de atividades paralelas de formação, na busca de uma experiência prática, muitas vezes distorcida e precoce, inclusive envolvendo remuneração financeira ${ }^{5,9,10}$. Portanto, é necessário investigar os cenários de atividades paralelas não apenas do ponto de vista das atividades técnicas que nestes se desenvolvem, mas também sob o aspecto ético, pois fazem parte importante da formação médica ${ }^{11}$ e participam do desenvolvimento do estudante como pessoa ${ }^{12}$.

\section{METODOLOGIA}

O estudo foi realizado sob a ótica de uma metodologia que envolve componentes quantitativos e qualitativos. O instrumento de coleta de dados foi constituído por um questionário com questões fechadas e abertas, objetivando-se a facilidade na aplicação e a inclusão de um número maior de sujeitos, mantendo-se a privacidade destes ${ }^{13-15}$.

Integraram a população estudada os 68 alunos que cursavam a quarta série do curso médico no período de realização da pesquisa. Destes, 63 participaram do estudo, visto que os demais não haviam cursado a terceira série no ano de 2003. O questionário foi aplicado entre outubro de 2004 e abril de 2005.

Os dados das questões fechadas foram inseridos e analisados pelo programa Epi-Info ${ }^{16}$, ao passo que as respostas às perguntas abertas receberam tratamento qualitativo, por intermédio da análise do discurso. Tal metodologia busca compreender como um objeto simbólico - o discurso - produz sentidos para e por sujeitos, permitindo obter interpretações variadas, apesar de mantidas as concepções teóricas ${ }^{17-19}$.

Todos os sujeitos assinaram um Termo de Participação, tendo sido a pesquisa previamente aprovada pelo Comitê de Ética em Pesquisa (CEP) da instituição.

\section{RESULTADOS E DISCUSSÃO}

Considerando-se o caráter qualitativo da maioria dos dados analisados, estes serão apresentados e discutidos na mesma seção deste trabalho.

\section{Caracterização da população estudada}

Na amostra composta pelos 63 alunos que responderam aos questionários analisados, observou-se prevalência do gênero feminino $(60,32 \%)$ em comparação com o masculino $(39,68 \%)$. Com relação à faixa etária, constatou-se que a maior porcentagem dos alunos se encontrava no intervalo compreendido entre 22 e 23 anos de idade (74,43\%).

Os dados obtidos mostraram também que mais da metade dos alunos investigados (60,32\%) eram procedentes do estado de Alagoas, sendo $89,47 \%$ da capital e 10,52\% do interior. Uma proporção significativa $(39,68 \%)$ provinha de outros estados.

Participação em atividades do currículo paralelo 
Praticamente todos os estudantes (98,41\%) buscaram algum tipo de atividade extracurricular durante a terceira série do curso médico no ano de 2003. Este quantitativo é mais elevado do que o identificado por Taquette ${ }^{9}$ num estudo realizado em outra Universidade, onde aproximadamente $10 \%$ dos estudantes do terceiro ano do curso freqüentavam algum estágio.

Contudo, considerando-se o curso como um todo, Menezes $^{20}$ assinalou que $64,6 \%$ dos estudantes consideram as atividades extracurriculares "fundamentais para a formação médica". Zimmer ${ }^{21}$ relatou que 93,9\% dos estudantes de um curso médico acreditavam ser necessária alguma atividade extracurricular para complementar sua formação. É interessante observar que, em que pese a tradição dos estágios extracurriculares na formação médica no Brasil, a literatura internacional aponta a obsolescência de tais atividades no contexto das instituições ${ }^{5}$.

Os processos pelos quais os estudantes ingressaram nas atividades encontram-se representados na Figura 2.

Figura 2 .

Processos de ingresso dos alunos em atividades extracurriculares.

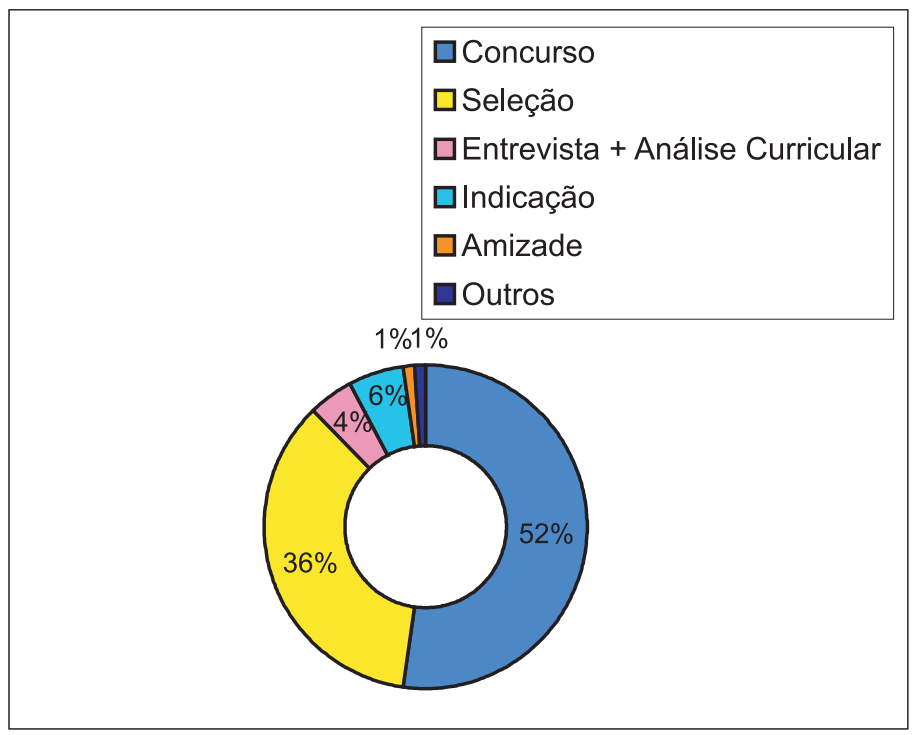

\section{Caracterização das atividades realizadas no currículo paralelo}

A análise dos locais das atividades buscadas pelos estudantes revelou a influência do currículo formal em todos os outros "currículos", como esperado. Fatores culturais da instituição, aspectos relacionados a docentes e a serviços, que, por suas características pessoais e institucionais, são mais valorizados pelos estudantes, determinam em grande grau a seleção das atividades buscadas espontaneamente por eles, tanto no ambiente acadêmico (currículo informal), como no currículo paralelo.

Assim, a grande oferta de vagas e o preenchimento por seleção (sem concurso) determinaram que 47,54\% realizassem estágio num hospital psiquiátrico da cidade. Esta realidade se relaciona à grande oferta de vagas por essa instituição e pode não refletir uma intencionalidade "seletiva" na especialidade eleita pelos estudantes, mas apenas ser a expressão da participação em algum tipo de atividade extramuros. Entretanto, a maior concentração de interesse referiu-se a diversos serviços de terapia intensiva, de emergência e de maternidade, nos quais os alunos se identificam não apenas com a representação do médico envolvido com situações complexas de ameaça à vida, mas também localizam possibilidades de realizar diversos procedimentos médicos. A preferência por estágios em serviços de emergência também foi constatada por Taquette ${ }^{9}$ e Menezes ${ }^{20}$, que identificaram, respectivamente, $43,8 \%$ e $26,2 \%$ de estudantes que buscaram tais atividades.

A duração dos estágios, em praticamente a metade dos casos, foi de seis meses, havendo, nos extremos da curva de distribuição, $5,88 \%$ que declararam estágios superiores a 12 meses e 13,24\% que não chegaram aos seis meses de duração. Um dos dados mais significativos desta pesquisa diz respeito à carga horária semanal dedicada aos estágios, demonstrada na Figura 3. 
Figura 3.

Tempo semanal despendido com cada estágio realizado.

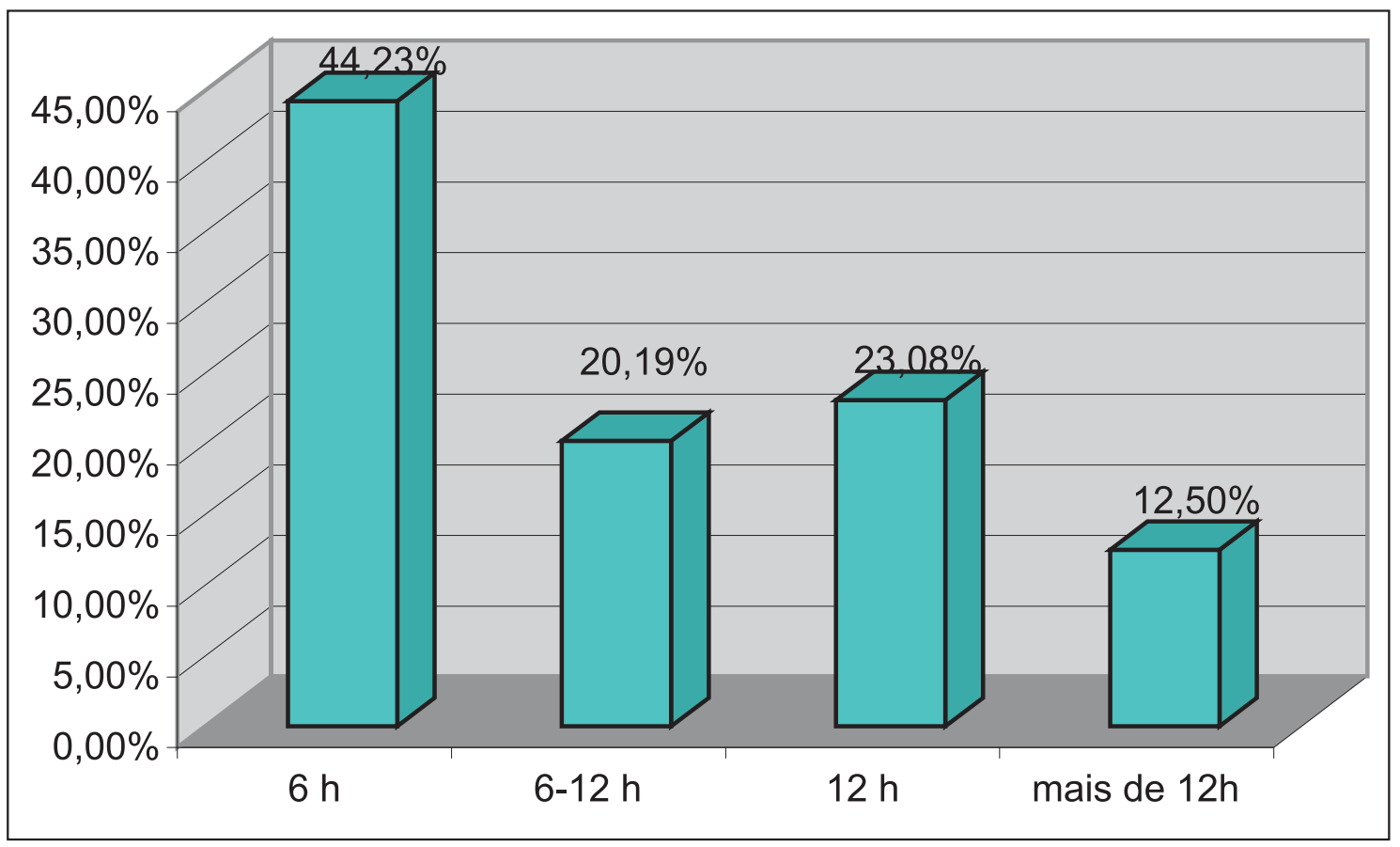

Observa-se que grande parte dos estágios (44,23\%) consome, em média, seis horas semanais. Entretanto, é importante salientar que a maioria destes $(55,77 \%)$ exige do aluno maior disponibilidade de tempo, uma vez que transcorre em mais de um turno do dia. Tal fato concorre para o prejuízo das atividades letivas, ao gerar falta às aulas na Universidade ou indisposição para cumprir os deveres acadêmicos presenciais ou não.

Esses dados evidenciam que as atividades do currículo paralelo ocupam um lugar importante na formação dos estudantes, ao menos no que diz respeito ao interesse e à dedicação. Esta realidade é ainda mais surpreendente se analisarmos que os dados foram coletados na terceira série do curso, momento em que, no currículo formal da escola estudada, tem lugar a disciplina de Semiologia. Portanto, os estudantes que freqüentam tais atividades curriculares ainda não foram capacitados na prática da anamnese, do exame físico e do diagnóstico clínico. A formação ocorre, assim, em duas realidades vivenciadas paralelamente de forma pouco integrada, envolvendo a Universidade e os serviços, contrariando as tendências contemporâneas de integração da academia com os cenários reais do SUS, mediante a construção de parcerias interinstitucionais ${ }^{22}$. Com efeito, as Diretrizes Curriculares Nacionais do Curso de Graduação em Medicina valorizam a diversificação dos cenários de formação, desde que seja mantida a coerência dos estágios com o Projeto Pedagógico do Curso, ao mesmo tempo em que ressaltam a responsabilidade da avaliação da aprendizagem pela instituição formadora ${ }^{23}$.

Motivação para atividades do currículo paralelo

A principal motivação apontada pelos estudantes para realizar atividades extracurriculares foi a "busca da prática" na formação $(36,27 \%)$, seguindo-se a "aquisição de novos conhecimentos" (30,39\%), conforme demonstrado na Figura 4. 
Figura 4 .

Motivações citadas pelos alunos como justificativa para a busca de atividades extracurriculares.

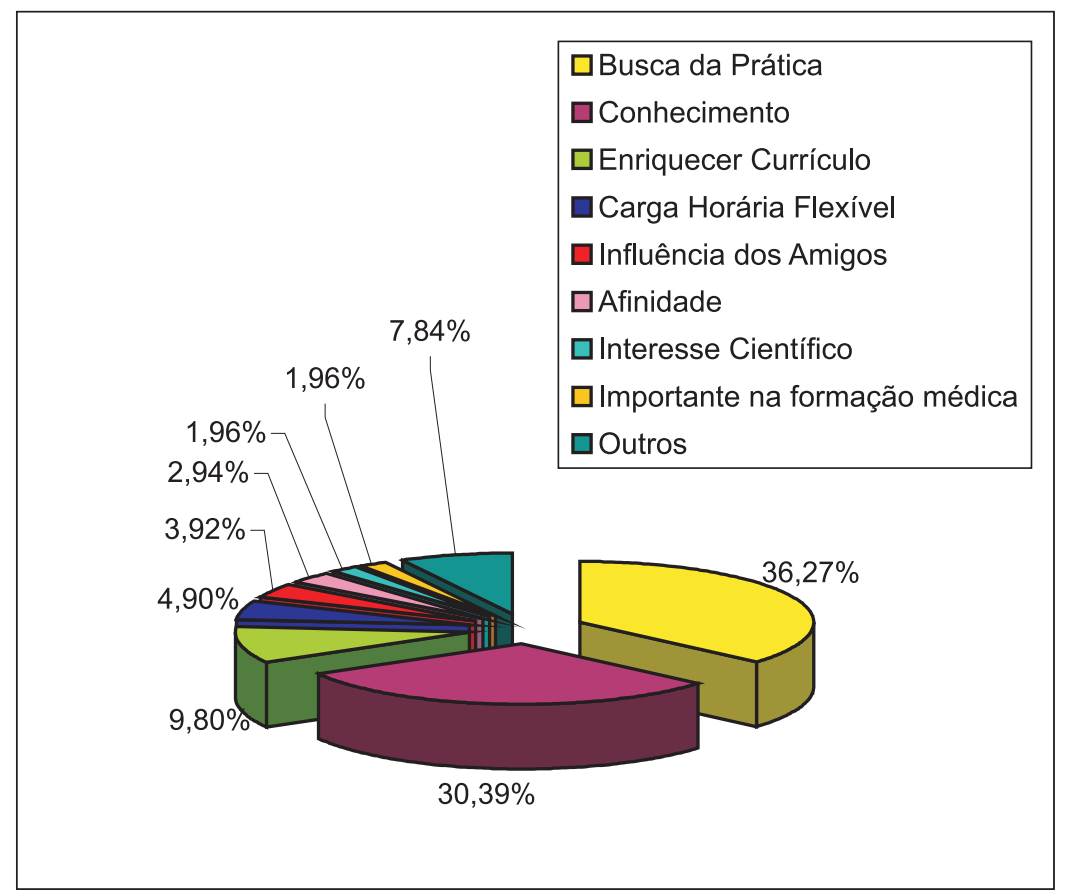

Dentre as expressões utilizadas pelos pesquisados na resposta à questão, foram observadas: "vivência na prática médica", "melhor aprendizado prático nos estágios", "maior aprendizado prático (...) e conhecer mais a rotina de trabalho de um médico", "desenvolver a relação médico-paciente, (...) desenvolver o aprendizado em atividades extras..." e "conhecer os mais diversos tipos de ambiente hospitalar". A necessidade de expandir a prática na formação, também discutida a seguir, é igualmente apontada por Taquette ${ }^{9}$, em cuja pesquisa a causa mais freqüente das atividades extracurriculares foi "aperfeiçoamento prático", uma vez que os estudantes de Medicina identificavam esta lacuna no currículo formal da instituição: $88,9 \%$ dos pesquisados identificavam "falta de integração teórico-prática no ensino" no currículo formal. Em outro estudo, Menezes ${ }^{20}$ relatou que $80,5 \%$ de estudantes da quinta série de um curso médico apontaram o fator "complementação do curso prático" como motivador para estágios realizados durante toda a graduação.

A percepção desta necessidade de complementação do currículo formal foi também identificada pelos estudantes da presente pesquisa. A exemplo de outros estudos ${ }^{5,21}$, foram identificadas críticas enfáticas ao currículo escolar, sobretudo no que diz respeito à escassez e à inserção tardia de atividades práticas. Algumas das respostas ao questionário incluíram: “a deficiência das aulas práticas oferecidas pelos professores; o número de aulas é insuficiente para o aprendizado", "o curso é falho em aulas práticas, o que leva o aluno a buscar experiência em outros hospitais", "a principal motivação é para o aprendizado no campo prático, visto que na nossa Universidade o curso de Medicina ainda é de embasamento principalmente teórico" e "chance de aprender algo mais (que provavelmente não aprenderia na faculdade)", dentre outras.

Mesmo quando a instituição oferecia atividades práticas, as críticas se referiam à quantidade de estudantes envolvidos: "Eu não gosto muito da enfermaria do HU porque os pacientes são atacados por uma porção de estudantes, às vezes até ao mesmo tempo, e isso não me agradava".

Contrapondo-se à "rota pedagógica" tradicional, segundo a qual o estudante precisa de uma ampla formação teórica antes de se aproximar do campo de práticas, evidenciou-se neste estudo que os estudantes realizam atividades extracurriculares com o propósito de antecipar experiências de formação que normalmente ocorrem em momentos mais tardios do curso, geralmente no internato. A prática profissional, considerada fundamental pelos estudantes na graduação, quando não é oferecida pelas escolas no currículo formal, é buscada nos estágios extracurriculares. Existe, contudo, o risco de a qualidade da formação ser 
comprometida, uma vez que muitos serviços podem não oferecer a supervisão adequada dos estudantes.

A questão do estágio como fonte de percepção financeira pelo estudante não emergiu dos dados desta pesquisa, embora mais da metade dos estudantes da amostra tenham despesas maiores de deslocamento e moradia por serem oriundos de outros estados ou do interior de Alagoas. Entretanto, as atividades remuneradas podem ser, dependendo das necessidades do estudante, um importante fator motivador. Zimmer $^{21}$ observou que 21,3\% de uma amostra de 165 estudantes de todas as séries de um curso médico eram motivados pela remuneração financeira para realizar atividades extracurriculares. Menezes ${ }^{20}$ referem que $45,8 \%$ dos estudantes da quinta série realizavam ou haviam realizado estágios remunerados.

\section{Currículo paralelo e desenvolvimento de competências profissionais}

Os dados das questões abertas podem ser analisados tomando-se como base um referencial teórico conceitual que deriva da formação norteada para o desenvolvimento da competência profissional, definida por Epstein e Hundert ${ }^{24}$, num importante trabalho publicado em 2002, nos seguintes termos: “... o uso habitual e criterioso de comunicação, conhecimento, habilidades técnicas, raciocínio clínico, emoções, valores e reflexão na praça cotidiana, para o benefício do indivíduo e da comunidade atendida" (p. 226).

Após uma extensa revisão na literatura internacional, os autores propõem sete dimensões da competência, que devem ser desenvolvidas no processo de formação profissional: cognitiva, técnica, integrativa, contextual, relacional, afetivomoral e de hábitos mentais.

Observamos que a ênfase conteudística dos currículos de formação tradicional de Medicina geralmente resulta na exigência da assimilação de um contingente expressivo de informações médicas, avaliadas, em geral, nas provas de aprendizagem e nos concursos de Residência Médica, dentre outros, porém muitas vezes desvinculadas da prática no contexto em que esta ocorre. É possível que os estudantes, após dois anos de ensino de disciplinas básicas, percebam lacunas de sua formação no currículo formal e busquem, em estágios fora da instituição, experiências que julguem relevantes para o seu desenvolvimento como futuros profissionais. Assim, quando afirmam que realizam estágios para "maior vivência da prática médica", "maior experiência e prática no curso médico" e "conhecer os mais diversos tipos de ambiente hospitalar", os estudantes realizam por si mesmos o movimento de diversificação de cenários de formação, que deveria ser de responsabilidade da escola.

Algumas falas identificam que o estudante não deseja apenas aprender algumas "técnicas", mas uma prática integrada com a teoria: "A necessidade de aprender e observar na prática o que foi aprendido na vida acadêmica e também aprender novos conceitos não explorados na Universidade".

Uma das dimensões da competência diz respeito exatamente à contextualização das ações. A prática numa enfermaria é certamente muito diferente da prática num ambulatório, num serviço de emergência ou num espaço da comunidade. A diversificação dos espaços pode estar, embora de forma não explícita, motivando os estudantes para a aprendizagem em múltiplos ambientes e com múltiplos formadores, não restritos aos docentes e aos preceptores da prática. Assim, alguns depoimentos apontam que os estudantes procuram estágios para "maior vivência da prática médica" e "conhecer os mais diversos tipos de ambiente hospitalar", dentre outros exemplos possíveis.

Os estudantes querem aprender medicina onde esta "realmente ocorre", identificando os espaços onde a supervisão é menos "formal" (como a de docentes e preceptores, nos espaços da academia) e a prática se apresenta mais "real", com relação às representações que os estudantes têm da profissão que escolheram.

No âmbito da dimensão relacional, os estudantes valorizam os estágios como oportunidades para o desenvolvimento de suas relações com o paciente e com os demais profissionais.

Por fim, a reflexão da e na prática é, por excelência, um fator que propicia afetividade e valores morais, necessários ao exercício humanizado da profissão. É possível que os profissionais que supervisionam estágios estejam distantes da academia e não compartilhem dos objetivos de formação humanística desta. Assim, é necessário promover discussões, no currículo formal, a respeito das experiências dos estudantes no currículo paralelo, valorizando as experiências nele vivenciadas, que dificilmente seriam encontradas no ambiente acadêmico propriamente dito. Nos estágios, o aluno está inserido com mais intensidade, com maior grau de autonomia e responsabilidade na prática, atuando em situações com grande potencial de formação, como nos casos do acolhimento e da transmissão de más notícias aos familiares, entre outros.

Estas possibilidades de formação não devem ser perdidas, podendo ser discutidas (e planejadas) conjuntamente em espaços que congreguem formadores originados da academia e dos serviços, com vistas à formação integral dos estudantes, aqui se destacando os componentes do currículo oculto, que são dificilmente identificáveis e menos ainda planejáveis. 
Um levantamento realizado nos Anais do Congresso Brasileiro de Educação Médica de $2005^{25}$ aponta que, dos cerca de 970 pôsteres apresentados, apenas quatro se voltavam para a investigação do currículo paralelo nas instituições participantes. Considerando-se que, segundo $\mathrm{Rego}^{5}$, este espaço oferece ao estudante uma possibilidade de desenvolvimento de sua "cultura profissional", é necessário intensificar os estudos sobre esta temática nas instituições formadoras de médicos em nosso meio.

\section{CONSIDERAÇÕES FINAIS}

O currículo paralelo é, na formação do estudante de Medicina brasileiro, uma realidade que não pode ser ignorada pelas escolas. É possível que o planejamento do currículo formal - escolarizando, a partir do contexto social, experiências consideradas relevantes para a formação do futuro profissional - esteja ocorrendo de forma equivocada, uma vez que praticamente todos os estudantes sentem necessidade de "complementar" sua formação com atividades extracurriculares.

Assim, a pesquisa que toma como objeto o currículo paralelo de uma escola fornece subsídios importantes para o constante replanejamento curricular, desvelando cenários e práticas que podem ser incorporados ao processo de desenvolvimento da competência profissional desejada.

Os dados desta pesquisa reforçam as tendências contemporâneas de inserir o estudante de Medicina na prática profissional desde os primeiros momentos do curso. É na prática, adequadamente planejada e supervisionada pela escola, que são desenvolvidas algumas das características essenciais da profissão, como a reflexão, a resolutividade, a integração do conhecimento teórico com as ações, a responsabilidade e as relações interpessoais, sendo todas estas dimensões da competência profissional.

É necessário, portanto, estabelecer e sustentar um diálogo entre a academia e os serviços, como uma estratégia indispensável à formação integral de estudantes de Medicina, voltada para a atenção integral à saúde da população brasileira. No planejamento do currículo formal, a "escolarização" de determinado estágio muito procurado pelos estudantes não significa trazê-lo para o "controle" da escola, mas garantir a adequada supervisão dos estudantes, valorizando-se a atuação dos profissionais dos serviços, que podem, por sua vez, realizar seu processo de educação permanente na instituição acadêmica.

Finalmente, deve-se ressaltar a dimensão ética do estudo do currículo paralelo pelas escolas médicas. Se, por um lado, os estágios extracurriculares podem oferecer oportunidades valiosas de aprimorar a formação, atividades realizadas em momentos inadequados do curso, em cenários pouco propícios ou com supervisão deficiente podem distorcer o processo de formação do estudante, pelo qual, de forma integral, a instituição é responsável perante a sociedade.

\section{REFERÊNCIAS}

1. Universidade Federal de Alagoas. Núcleo de Ensino Médico. Projeto de reestruturação do curso médico da UFAL. 2002. [mimeo].

2. Dussel I, Caruso M. A invenção da sala de aula: uma genealogia das formas de ensinar. São Paulo: Moderna; 2003.

3. Goodson IF. Currículo: teoria e história. 5 ed. Petrópolis, RJ: Vozes; 2002. Cap.: Currículo: a invenção de uma tradição.

4. Maia JA. O currículo no ensino superior em saúde. In: Batista NA, Batista SH, orgs. Docência em saúde: temas e experiências. São Paulo: Senac; 2004. p.102-133.

5. Rego S. Currículo paralelo em Medicina, experiência clínica e PBL: uma luz no fim do túnel? Interface. 1998; 2(3): 35-48.

6. Maia JA. Formação humanística no ensino superior em saúde: intencionalidades e acasos. In: Batista NA, Batista $\mathrm{SH}$, Abdalla IG, orgs. Ensino em saúde: visitando conceitos e práticas. São Paulo: Arte e Ciência; 2005.

7. Silva TT. Documentos de identidade: uma introdução às teorias do currículo. 2 ed. Belo Horizonte, MG: Autêntica; 2004.

8. Brasil. Ministério da Saúde; Ministério da Educação. Programa nacional de reorientação da formação profissional em saúde: pró-saúde. Brasília: MS/MEC; 2005.

9. Taquette SR, Costa-Macedo LM, Alvarenga FBF. Currículo paralelo: uma realidade na formação dos estudantes de medicina da UERJ. Rev Bras Educ Med. 2003; 27(3): 171-6.

10. Ambrósio MR, Spíndola EB, Santos GT, Paiva HCF, Pacheco LF, Patrocínio LG, et al. Exercício profissional da Medicina por estudantes. Rev Bras Educ Med. 2001; 25(3): 28-38.

11. Venturelli J, Fiorini VML. Programas educacionais em escolas médicas: capacitação docente. Rev Bras Educ Med. 2001; 25(3): 7-21.

12. Busnello EDA, Marocco P, Costa BM, Maia HE, Hidalgo MPL, Marquardt A, et al. Desafio na psiquiatria: um ensino mais humanístico. Rev Bras Educ Med. 1997; 21(2-3): 13-6.

13. Cervo AL, Bervian PA. Metodologia científica: para uso dos estudantes universitários. 3 ed. São Paulo: McGrawHill; 1983. 
14. Thiollent M. Metodologia da pesquisa-ação. 4 ed. São Paulo: Cortez; 1988.

15. Geraldes AAR, Montenegro ELL. A confecção e o uso do questionário como instrumento de pesquisa. Rev Hospital Univ UFAl. 2000; 4-5(1-2): 7-16.

16. Organização Mundial da Saúde; Centers for Disease Control and Prevention. Epi-Info [software]. Versão 3.3.2.

17. Gregolin MRV. Olhares oblíquos sobre o sentido no discurso. In: Gregolin MRV, Baronas RL, orgs. Análise do discurso: as materialidades do sentido. São Carlos, SP: Claraluz; 2001. p.2-16.

18. Orlandi EP. A linguagem e seu funcionamento: as formas do discurso. 4 ed. Belo Horizonte,MG: Pontes; 2001. Cap.: Uma questão da leitura: a noção de sujeito e a identidade do leitor.

19. Maingueneau D. Termos-chave na análise do discurso. Belo Horizonte,MG: UFMG; 2000.

20. Menezes M, Sá ALV, Benevides IBS, Lamas APB, Kerner EG, Spinola AG, et al. O currículo paralelo no curso médico: riscos e benefícios. In: Resumo dos trabalhos do XLIII Congresso Brasileiro de Educação Médica. Rev Bras Educ Med. [CD-ROM]. 2005; 29(2 Supl.1): 174.

21. Zimmer LP, Hidalgo MPL, Rodrigues RO, Martins CD, Machado SR, Zimmer PM. Currículo oficial e currículo paralelo na Faculdade de Medicina da UFRGS. Rev Bras Educ Med. 1993; 17(3): 25-7.

22. Oliveira NA. O SUS e o ensino médico: desafios e perspectivas. In: Resumo dos trabalhos do XLIII Congresso Brasileiro de Educação Médica. Rev Bras Educ Med. [CDROM]. 2005; 29(2 Supl.1): 243-4.

23. Brasil. Ministério da Educação. Conselho Nacional de Educação. Câmara de Educação Superior. Resolução CNE/ CES $n^{\circ} 4$ de 7 de novembro de 2001. Institui diretrizes curriculares nacionais do curso de graduação em Medicina. Diário Oficial da União. Brasília, 9 nov. 2001; Seção 1, p.38.

24. Epstein RM, Hundert EM. Defining and assessing professional competence. JAMMA. 2002; 287(2): 226-35.

25. Resumo dos trabalhos do XLIII Congresso de Educação Médica. Rev Bras Educ Med. [CD-ROM]. 2005; 29(2 Supl.1): 1-585.

\section{CONFLITO DE INTERESSE:}

Declarou não haver.

\section{ENDEREÇO PARA CORRESPONDÊNCIA}

Carlos Henrique Falcão Tavares

Hospital Universitário Professor Alberto Antunes - Ufal

Departamento de Tocoginecologia e Pediatria

57061-970 - Maceió -AL

E-mail: carloshenri@rocketmail.com 